\title{
Do Community-Based Programs Help to Improve HIV Treatment and Health Outcomes? A Review of the Literature
}

\author{
Ugo Amanyeiwe ${ }^{1}$, Suzanne Leclerc-Madlala ${ }^{1}$, Hannah Gardi ${ }^{2}$ \\ ${ }^{1}$ US Agency for International Development, Washington DC, USA \\ ${ }^{2}$ Greater Homewood Community Corporation, Baltimore, USA

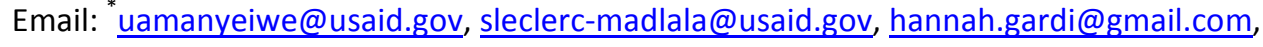

Received 20 June 2014; revised 15 July 2014; accepted 11 August 2014

Copyright (C) 2014 by authors and Scientific Research Publishing Inc.

This work is licensed under the Creative Commons Attribution International License (CC BY). http://creativecommons.org/licenses/by/4.0/

(c) †) Open Access

\begin{abstract}
Increased availability of antiretroviral treatment for HIV makes the goal of universal access attainable. However, in most resource constrained settings where existing health systems are largely dysfunctional, major barriers to achieving this goal remain. While treatments with antiretroviral drugs (ART) are the focal point of HIV management, it is increasingly recognized that ART alone will not be sufficient to adequately deal with the lifelong consequences of the disease. In addition, the current global economic downturn will continue to impact on funding for HIV care and support, making the search for sustainable solutions more urgent. This article reviews the current evidence base on the impact of community-based programs on HIV/AIDS treatment and general health outcomes, as well as their contribution to ensuring sustained care for HIV-positive people. Our findings suggest that these programs overall have a positive impact on various dimensions of HIV treatment and care, and make a significant contribution to health and HIV outcomes. The authors argue that better use of community platforms for HIV treatment and care programs could be critical for attaining desired goals and should be prioritized at all levels of program design, implementation, and monitoring and evaluation.
\end{abstract}

\section{Keywords}

HIV/AIDS, ARV Treatment, Care, Community-Based Programs

\section{Introduction}

In this era of increased availability of antiretroviral therapy (ART) for treatment of HIV/AIDS, the World Health Organization's goal of universal access to comprehensive HIV prevention, treatment, and care seems attainable

${ }^{*}$ Corresponding author.

How to cite this paper: Amanyeiwe, U., Leclerc-Madlala, S. and Gardi, H. (2014) Do Community-Based Programs Help to Improve HIV Treatment and Health Outcomes? A Review of the Literature. World Journal of AIDS, 4, 311-320. 
[1] [2]. However, realizing this goal will be challenging, particularly in resource-limited regions where existing health systems are fragmented and weak and there are insufficient operational resources for delivering required services. In these settings, and in addition to a range of biomedical matters to deal with, there are structural issues of program design and service delivery to be considered, as well as socio-cultural challenges including those related to targeting of key populations.

Overall, ART has transformed HIV from a fatal disease to a chronic illness. New HIV infections fell 21\% worldwide between 1997 and 2010, and since 2001, the estimated number of people living with HIV has increased $17 \%$ to 34 million [3]. These statistics highlight the importance of addressing the entire trajectory of the disease over a person's lifetime, from diagnosis onward. Research shows that without support, adherence to treatment decreases, which in turn can lead to drug resistance [4] [5]. Beyond appropriate medical treatment, other services are required for achieving a successful continuum of care among HIV patients, including the provision of psychological care and support. This often comprises nonclinical, community-based services such as, but not limited to, spiritual, legal and economic support. While psychological care and support can come from staff at the health facility treating the patient, several studies have demonstrated that support is more effective when coming from a focused, on-going program in the community where the patient resides [6]-[9].

Just as support is needed for individual treatment adherence and retention in care, a re-evaluation of the entire health care system may be needed to ensure universal access to long-term care for HIV patients. As HIV has transitioned from being an acute disease to being a chronic illness, so too must the global HIV response transition from one guided by a predominantly medical model to one guided by a more interdisciplinary model of comprehensive care. ART is reaching more people than ever before. Yet in 2011 a total of $47 \%$ of people with HIV in need of ART did not have access to treatment [2], most of who lived in rural and hard-to-reach areas. In order to increase access, a paradigm shift in the way the global health community thinks about HIV/AIDS service provision may be necessary. There is a growing consensus that the conventional model of health care delivery is not sufficiently addressing the complex challenges of HIV prevention, treatment, and care [10] [11].

\section{A Call to Action}

Funding constraints from the global economic crisis persist, and national governments and the international community are reassessing fiscal priorities. While treatment with antiretrovirals is the focal point of HIV management, it is increasingly recognized that treatment alone is not enough to adequately deal with the lifelong consequences of contracting HIV. Beyond the physical consequences of long-term ART, there is a growing body of literature that examines the role of community-based programs in addressing ART's long-term social and psychological consequences. Taking into account the changing needs of the epidemic, including increased survival rates for people living with HIV on ART, it has been estimated that by 2017, 1.5 to 3 times the current number of health care workers (depending on the world region) will be needed to provide $100 \%$ coverage to people living with HIV [12]. In 2006, 4.3 million additional trained health workers were needed globally [13]. Workforce shortfalls will likely be the greatest in the poorest countries. Therefore, developing innovative programs that leverage community assets while employing task-shifting for efficient use of resources may help governments to provide services for people previously considered out of reach.

Works by Brown et al. [14], Battles \& Wiener [15], Ledie [16], and Domek [17] all attest to the positive and vital role that such programs can play in helping HIV-positive children make the kinds of psychosocial adjustments associated with the challenges of long-term survival of HIV. Increasingly researchers are arguing for a comprehensive package of treatment, care and prevention of onward transmission, implemented at the local level, as the most effective way to deal with the current and long-term needs of HIV patients. In spite of limited research in the form of randomized control trials, there is growing evidence that community-based programs can play an important role in improving treatment and health outcomes [18]-[24].

In this article, we review the literature to assess the current evidence on the role and impact of communitybased programs on HIV/AIDS treatment and health outcomes for people living with HIV.

\section{Methods}

\subsection{Search Strategy}

In June 2012, the authors undertook a search of the following databases for articles on the relationship between 
health outcomes and community-based practices related to HIV treatment, care and support: Medline, Academic Search Premier, PubMed, Family and Society Studies Worldwide, Global Health, CINAHL, ERIC, SocIndex, Google Scholar, and Social Work Abstracts. We set the search perimeters for a ten-year window from June 2002 to June 2012. The search terms included community-based/home-based/palliative care/community health worker / expert patient", and morbidity/adherence/retention/disclosure/stigma/health/outcomes, and HIV/AIDS. In the documents resulting from this search, we examined the references cited to identify additional research articles of value. We also looked at gray literature such as program evaluations, reports, and toolkits because they provide information about recent community-based projects.

The criteria for inclusion in the literature review were as follows: 1) the article was original research written in English; 2) the subjects were from low- and middle-income countries, categorized according to the World Bank system of classification; and 3) the study discussed HIV service provision regarding community-based programs and treatment outcomes for people living with HIV/AIDS on ART or those not yet eligible for HIV treatment but accessing treatment for opportunistic infections (OIs) and enrolled in care. Studies that incorporated elements of community-based programs but did not explicitly state this were also included.

Our research focused on low- and middle-income countries that, for the most part, have had to use innovative strategies to address the HIV epidemic. Unlike most reviews that focused solely on sub-Saharan Africa [25][27], we took a broader perspective, aiming to glean additional insight from multiple regional contexts. We reviewed research from Africa $(n=62)$, Asia $(n=8)$, Latin America $(n=5)$, and studies that included multiple countries $(n=12)$.

\subsection{Analysis}

The search yielded a total of 1569 articles referring to the subject matter. After sorting to identify the studies based on research conducted in low- and middle-income countries, 489 articles remained. Abstracts of these were reviewed and 74 met the inclusion criteria described above. An additional 11 articles were added from bibliographies, hand searches, and consultations with experts, yielding a total of 90 articles for review.

The researchers used a recognized appraisal tool, the Johns Hopkins nursing evidence-based practice: research evidence appraisal tool [28] to grade the 90 studies (See Table 1). Studies were then grouped by outcome measures and policy recommendations, with outcomes including the following: viral load, adherence to treatment, loss to follow-up, increased disclosure, stigma reduction, task shifting, and cost effectiveness. Concurrently, the review also examined the relationship between facility-based and community-based services. Without appropriate study designs or standardized outcome measures, statistical pooling of results was not possible; therefore, a formal meta-analysis was not undertaken.

\section{Results}

Literature on this topic remains limited. Due to the nature of the HIV/AIDS epidemic (which involves social stigma), randomized control trials (RCTs) are often not the ethical choice for use during an intervention that requires service provision to those in need while meeting rigorous data collection requirements [29] [30]. Our review indicated that the majority of studies used some form of sampling controls at the time of the intervention. Therefore, this review included a range of studies from RCTs to program evaluations. To mitigate concerns about scientific rigor, Table 2 presents a synthesis of the research evidence showing quality and quantity of the studies, based on the weighed evaluation reflected in Table 1.

Of the 90 articles reviewed six reported on the limitations of community-based HIV treatment programs [21] [31]-[35]. The vast majority of articles provided evidence on the positive role of the community in enhancing HIV care and treatment outcomes. Beyond posing the broad question "do community-based programs impact the fight against HIV?" we paid special attention to studies that revealed in what ways do community-based programs impact the health or wellbeing of people living with HIV.

\subsection{Stigma and Disclosure}

On the topic of community-level stigma, research has shown a strong correlation between disclosure of HIV status and retention in care [36] [37]. Studies reveal that disclosure increases as stigma is mitigated [38] [39]. Forty-two studies in the review argued that the community should be the main platform for addressing issues of 
Table 1. Research evidence category appraisal tool.

\begin{tabular}{ll}
\hline Level I: & $\begin{array}{l}\text { Randomized Controlled Trials (RCT); experimental studies; or systematic reviews of RCTs with or without } \\
\text { meta-analysis }\end{array}$ \\
Level II: & $\begin{array}{l}\text { Quasi-experimental studies; systematic reviews of a combination of RCTs and quasi-experimental studies or } \\
\text { quasi-experimental studies only, with or without meta-analysis }\end{array}$ \\
& $\begin{array}{l}\text { Non-experimental studies; qualitative studies; systematic review of a combination of RCTs, quasi-experimental } \\
\text { and non-experimental studies or non-experimental studies, only with or without meta-analysis; systematic review } \\
\text { of qualitative studies, with or without meta-synthesis }\end{array}$ \\
Level III: & $\begin{array}{l}\text { Opinion of respected authorities and/or reports of nationally recognized expert committees based on scientific } \\
\text { evidence }\end{array}$ \\
Level IV: & $\begin{array}{l}\text { Evidence obtained from literature reviews, quality improvement documents, program evaluation, financial evalu- } \\
\text { ations, case studies, or opinions of nationally recognized experts based on experimental evidence }\end{array}$ \\
\hline
\end{tabular}

Note: The research evidence categories are drawn from Johns Hopkins Nursing Evidence-Based Practice: Research Evidence Appraisal Tool (Dearholt \& Dang, 2012).

\section{Table 2. Quality rating based on quality appraisal tool.}

consistent, generalizable results; sufficient sample size for the study design, adequate control; definitive conclu-
A-High Quality
sions; consistent recommendations based on comprehensive literature review that includes thorough reference to
scientific evidence
reasonably consistent results; sufficient sample size for the study design; some control; fairly definitive conclu-
sions; reasonably consistent recommendations based on fairly comprehensive literature review that includes
some references to scientific evidence

Note: The quality ratings are drawn from Johns Hopkins Nursing Evidence-Based Practice: Research Evidence Appraisal Tool (Dearholt \& Dang, 2012).

stigma and disclosure. One study that examined the barriers to HIV service provision found that the main reason people do not access testing and treatment was fear of stigma and discrimination [40]. Three other studies found a strong correlation between social support structures that promote anti-stigma education and improved health outcomes for people living with HIV [36]-[38]. Clinical outcomes in these studies ranged from suppression of viral load to improved quality of life indicators.

\subsection{Viral Load}

Using the outcome of decreased viral load, one cohort study demonstrated that community-based ART programs could be an effective alternative model to facility-based HIV treatment. After two years, $86 \%$ of active patients in the study had a viral load of less than 400 copies per millilitre [41]. Twenty-one of the studies reported decreases in viral load associated with community-based programs. Of these, 15 are high quality RCTs or quasiexperimental studies and the remaining are high quality program evaluations. The 15 RCTs and quasi-experimental studies all provided quantitative outcome data.

\subsection{Adherence}

Treatment adherence is implicit for decreased viral loads throughout the continuum of care. Half of the articles reviewed $(n=45)$ included some discussion of the importance of adherence to treatment protocols. The data indicate that increased community support correlates with improved adherence, which results in decreased loss to follow-up and mortality [8] [9] [18] [24] [42] [43].

However, in a number of articles $(\mathrm{n}=14)$ that discussed the two treatment modes (facility-based and community-based care) at length, some divergence was seen on recognition of improved health outcomes. There were varying suggestions as to the kind of relationship health facilities should have with the community. While most all of the evidence in this review pointed to the benefits of community support, an on-going question remains: To yield the best results, what is the optimal type and degree of collaboration between HIV treatment facilities 
and community-based organizations [7] [8] [20] [44]-[46].

\subsection{Cost-Effectiveness}

Similarly, there is varying evidence on the cost-effectiveness of community-based versus facility-based treatment. Of the six articles that discussed the cost construct of community-based programming, four reported that community-based ART is the most cost-effective option in resource-limited settings [20] [45] [47] [48]. In contrast, an article by Babigumira, Sethi, Smyth, and Singer [31] concluded the opposite, that facility-based care is the most cost-effective option. However, Babigumira et al. also argue that community-based treatment programs result in the best health outcomes for patients.

\section{Discussion}

Our review of the existing literature indicates that the implementation of specific non-clinical/community-based interventions contribute to improved HIV treatment and health outcomes. This corroborates the findings from previous review studies on the topic such as that by Barnighausen et al. [12] and Wouters et al. [49]. Further research is required to ascertain more precisely which interventions are most effective in treating HIV in a community setting and which interventions best meet the needs of individual patients. For service providers, program developers, and policymakers, more research is needed to identify which components of a basic continuum of care, across clinical and community-based services best address patient needs in an integrated manner. It should be noted that none of the articles reviewed stated categorically that the facility setting or the community setting was better for providing HIV care. Programs that produced favourable HIV treatment and health outcomes were largely those where services were provided across both settings, as a continuum of care. A hallmark of these programs was a formally established affiliation between the facility-based programs and community-based programs whereby both worked together. These partnerships involved patients being enrolled in community-based support programs as well as strong facility treatment services [8] [9] [18] [24] [42]-[43].

While evidence for improved treatment outcomes in the context of formalized facility-community support structures is strong, it still appears to be the case that few facility-based programs have formalized linkages with community-based interventions [18] [20] [44]-[46]. The success of a formalized facility-community approach to the continuum of HIV care and treatment is mostly attributed to the strong working relationships between clinical and nonclinical programs. Through a formalized bi-directional referral system, people living with HIV and their caregivers would have access to a wider range of HIV services (see Figure 1). Additionally, by creating a comprehensive network of service provision, researchers argue that patients are less likely to be lost to follow-up and more likely to adhere to treatment regimens. Furthermore, as expanded public information messages about HIV prevention, treatment and care, as well as other education efforts reach people within the community, stigma toward HIV sero-positive status reportedly decreases and people living with HIV are more likely to seek out and take advantage of the available services.

The research evidence indicates a comprehensive continuum of care across health facilities and communitybased programs may be the most sustainable way to improve treatment outcomes and quality of life for people living with HIV. This raises questions about the cost of long-term treatment and care for these patients. As this segment of the population lives longer with the aid of ART, the overall cost of treatment and care increases. Based on the studies reviewed, the majority of researchers found that community-based services are the most cost-effective option in resource-limited settings [20] [45] [47] [48]. For a sustainable community health infrastructure to succeed there would need to be willingness among funding entities (government agencies and donors) to invest in developing community-based systems and programs that complement the traditional health sector. Just as there is a focus on building strong institutional capacity for evidence-based practices, supportive supervision, and monitoring and evaluation for facility-based care, the same should be required for community-based care and services. By formalizing these support structures at both the facility level and the community level, countries could create a comprehensive, outcome-driven and sustainable service delivery system benefitting health care in general and HIV prevention, treatment, and care in particular.

\subsection{Strengths}

This article provided an overview of research to date examining the impact of community-based HIV programs 


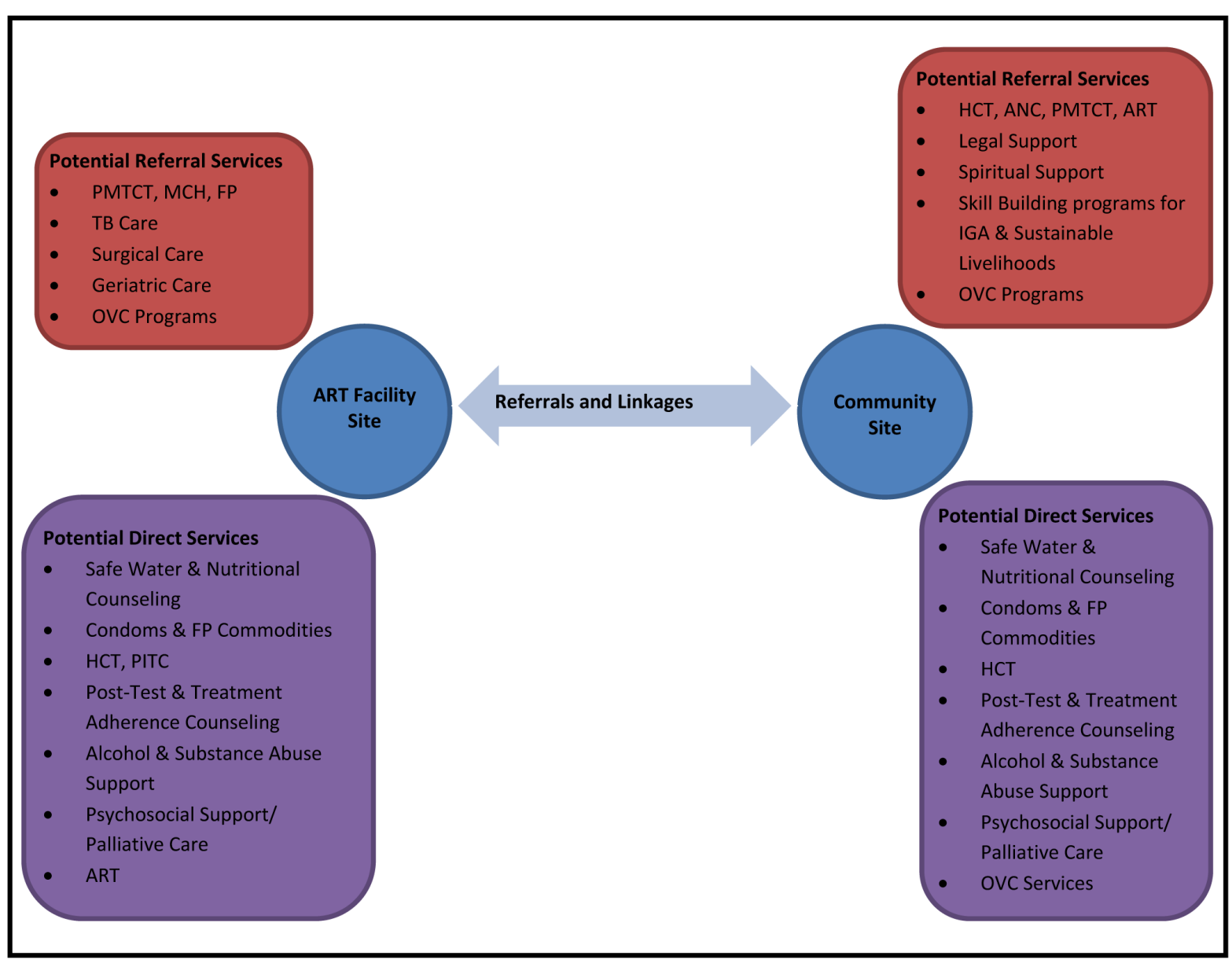

Figure 1. Continuum of care and support across facility and community settings.

on treatment and care outcomes. By analysing 90 articles, the authors were able to examine a broad range of service provision methods and country-specific examples. Similarly, by examining randomized control trials (RCTs), quantitative, qualitative, mixed methods, and program evaluation research approaches, the authors were able to determine the relationship between community-based programs and health outcomes, information that is useful for program planning and policy development at all levels. During the course of the review the authors did not come across a previous publication that looked specifically at how community-based HIV programs impact treatment outcomes; thus, this work is a contribution to that important topic.

\subsection{Limitations}

It proved challenging to find relevant RCTs being conducted on the impact of community-based care on HIV treatment outcomes. Therefore, the review included evaluation research and program case studies not typically found in routine peer-reviewed literature. The authors did not include literature reporting on community-based activities in other HIV-related areas such as prevention. Because this review focused on treatment and care, the authors elected not to use a number of studies that showed successful outcomes when communities and facilities collaborate in prevention initiatives such as outreach programs that increase community awareness.

\section{Conclusions}

The literature overwhelmingly attests to a positive relationship between community-based programs and improved HIV treatment outcomes in resource-limited settings. As healthcare for people living with HIV progresses to lifetime chronic care, it is vital that the global HIV community shift its focus from a predominantly facilities-based model of care delivery to one that is more decentralized and potentially more sustainable. Based 
on the evidence provided by studies carried out in resource-limited settings-which account for the greatest burden of HIV globally_-more emphasis needs to be placed on identifying suitable community platforms that can be leveraged to offer HIV services in the community setting. Partnering with existing facility-based structures, these platforms can provide cost-effective HIV services that meet the needs of people in the community. Formalizing the relationship between facility-based and community-based service provision through regulated supervision, outcome attainment, and monitoring and evaluation would help to strengthen such programs. Policymakers and other stakeholders need to recognize the potential cost savings to be gained by engaging existing community-based structures in the delivery of HIV services in a locally monitored continuum of care. Policy reform is required to formalize and validate collaborative partnerships between health facilities and community platforms tasked with delivery of services to people living with HIV.

An ideal continuum of care would extend beyond the partnership of health facilities and communities to include relationships between communities, donor agencies, and the host country governments. Because each community setting has unique characteristics, we suggest three important factors to be taken into account for creating a basic care package to provide improved treatment outcomes for people living with HIV: 1) the specific sociocultural context, 2) the status of the formal health system, and 3) the community's knowledge, attitudes and practices regarding HIV and people living with HIV. In contrast to the "one-size-fits-all" minimum packages that are commonly promoted, countries planning to implement a continuum of care program for HIV patients would need to reach a consensus with all relevant stakeholders regarding tailoring for what to include in specific care packages.

Current evidence indicates that community-based care and support are a viable solution to addressing the complex problems associated with increased demand for HIV services resulting from people living longer with the disease. The evidence shows that such programs are cost effective and contribute to improved health outcomes in resource-limited settings. It is now up to the global HIV community to strategically support implementation of community-based HIV/AIDS programs that complement and synergize with clinical services, thereby ensuring increasingly sustained improvement in treatment outcomes.

\section{References}

[1] World Health Organization (2010) Will We Achieve Universal Access to HIV/AIDS Services with the Health Workforce We Have? A Snapshot from 5 Countries. WHO, Geneva.

[2] World Health Organization (2011) Global Health Sector Strategy on HIV/AIDS, 2011-2015. WHO, Geneva.

[3] UNAIDS (2011) World AIDS Day Report 2011: How to Get to Zero: Faster, Smarter, Better. The Joint United Nations Program on HIV/AIDS, Geneva.

[4] Bennett, D.E., Jordan, M.R., Bertagnolio, S., Hong, S.Y., Ravasi, G., McMahon, J.H., Saadani, A. and Kelley, K.F. (2012) HIV Drug Resistance Early Warning Indicators in Cohorts of Individuals Starting Antiretroviral Therapy between 2004 and 2009: World Health Organization Global Report from 50 Countries. Clinical Infectious Diseases, 54, S280-S289.

[5] Hong, S.Y., Nachega, J.B., Kelley, K., Bertagnolio, S., Marconi, V.C. and Jordan, M.R. (2011) The Global Status of HIV Drug Resistance: Clinical and Public-Health Approaches for Detection, Treatment and Prevention. Infection Disorders and Drug Targets, 11, 124-133.

[6] Igumbor, J.O., Scheepers, E., Ebrahim, R., Jason, A. and Grimwood, A. (2011) An Evaluation of the Impact of a Community-Based Adherence Support Programme on ART Outcomes in Selected Government HIV Treatment Sites in South Africa. AIDS Care, 23, 231-236.

[7] Taylor, B. and Hortas, L. (2006) Clinical Results Show Integrating Medical Care with Community Supports Is Key to Successful Outcomes for HIV Patients in Resource-Limited Settings. Cengage Learning, Farmington Hills. http://www.thefreelibrary.com

[8] Weidle, P.J., Wamai, N., Solberg, P., Liechty, C., Sendagala, S., Were, W., Mermin, J., Buchacz, K., Behumbiize, P., Ransom, R.L. and Bunnell, R. (2006) Adherence to Antiretroviral Therapy in a Home-Based AIDS Care Programme in Rural Uganda. Lancet, 368, 1587-1594.

[9] Zachariah, R., Teck, R., Buhendwa, L., Fitzerland, M., Labana, S., Chinji, C., Humblet, P. and Harries, A.D. (2007) Community Support Is Associated with Better Antiretroviral Treatment Outcomes in a Resource-Limited Rural District in Malawi. Transactions of the Royal Society of Tropical Medicine and Hygiene, 101, 79-84.

[10] Hagopian, A., Micek, M.A., Vio, F., Gimbel-Sherr, K. and Montoya, P. (2008) What If We Decided to Take Care of Everyone Who Needed Treatment? Workforce Planning in Mozambique Using Simulation of Demand for HIV/AIDS 
Care. Human Resources for Health, 6.

[11] Maddison, A.R. and Schlech, W.F. (2010) Will Universal Access to Antiretroviral Therapy Ever Be Possible? The Health Care Worker Challenge. Canadian Journal of Infectious Diseases \& Medical Microbiology, 21, e64-e69.

[12] Bärnighausen, T., Bloom, D.E. and Humair, S. (2007) Human Resources for Treating HIV/AIDS: Needs, Capacities, and Gaps. AIDS Patient Care and STDs, 21, 799-812. http://dx.doi.org/10.1089/apc.2007.0193

[13] Global Health Workforce Alliance [GHWA] (2008) Scaling up, Saving Lives. Task Force for Scaling up Education and Training for Health Workers. WHO, Geneva.

[14] Brown, L.K., Lourie, K.L. and Pao, M. (2000) Children and Adolescents Living with HIV and AIDS: A Review. Journal of Child Psychology and Psychiatry, 41, 81-96. http://dx.doi.org/10.1017/S0021963099004977

[15] Battles, H.B. and Weiner, L.S. (2002) From Adolescence through Young Adulthood: Psychosocial Adjustment Associated with Long-Term Survival of HIV. Journal of Adolescent Health, 30, 161-168. http://dx.doi.org/10.1016/S1054-139X(01)00341-X

[16] Ledile, S.W. (2001) The Psychosocial Issues of Children with Perinatally Acquired HIV Disease Becoming Adolescents: A Growing Challenge for Providers. AIDS Patient Care and STDs, 15, 231-236. http://dx.doi.org/10.1089/10872910152050748

[17] Domek, G.J. (2006) Social Consequences of Antiretroviral Therapy: Preparing for the Unexpected Futures of HIVPositive Children. Lancet, 367, 1367-1369. http://dx.doi.org/10.1016/S0140-6736(06)68584-X

[18] Arem, H., Nakyanjo, N., Kagaayi, J., Mulamba, J., Nakigozi, G., Serwadda, D., Quinn, T.C., Gray, R.H., Bollinger, R.C., Reynolds, S.J. and Chang, L.W. (2011) Peer Health Workers and AIDS Care in Rakai, Uganda: A Mixed Methods Operations Research Evaluation of a Cluster-Randomized Trial. AIDS Patient Care and STDs, 25, 719-724. http://dx.doi.org/10.1089/apc.2010.0349

[19] Bekker, L.G., Myer, L., Orrell, C., Lawn, S. and Wood, R. (2006) Rapid Scale-Up of a Community-Based HIV Treatment Service: Programme Performance over 3 Consecutive Years in Guguletu, South Africa. South African Medical Journal, 96, 315-320.

[20] Kipp, W., Konde-Lule, J., Rubaale, T., Okech-Ojony, J., Alibhai, A. and Saunders, D. (2011) Comparing Antiretroviral Treatment Outcomes between a Prospective Community-Based and Hospital-Based Cohort of HIV Patients in Rural Uganda. BMC International Health and Human Rights, 11, 12. http://dx.doi.org/10.1186/1472-698X-11-S2-S12

[21] Krebs, D.W., Chi, B.H., Mulenga, Y., Morris, M., Cantrell, R.A., Mulenga, L., Levy, J., Sinkala, M. and Stringer, J.S. (2008) Community-Based Follow-Up for Late Patients Enrolled in a District-Wide Programme for Antiretroviral Therapy in Lusaka, Zambia. AIDS Care, 20, 311-317. http://dx.doi.org/10.1080/09540120701594776

[22] Nglazi, M.D., Lawn, S.D., Kaplan, R., Kranzer, K., Orrell, C., Wood, R. and Bekker, L.G. (2011) Changes in Programmatic Outcomes during 7 Years of Scale-Up at a Community-Based Antiretroviral Treatment Service in South Africa. JAIDS Journal of Acquired Immune Deficiency Syndromes, 56, e1-e8. http://dx.doi.org/10.1097/QAI.0b013e3181ff0bdc

[23] Rodriguez-Garcia, R., Bonnel, R., N’Jie, N., Olivier, J., Pascual, F.B. and Wodon, Q. (2011) Analyzing Community Responses to HIV and AIDS: Operational Framework and Typology. World Bank Policy Research Working Paper No. 5532. The World Bank, New York.

[24] Wouters, E., van Loon, F., van Rensburg, D. and Meulemans, H. (2009) Community Support and Disclosure of HIV Serostatus to Family Members by Public-Sector Antiretroviral Treatment Patients in the Free State Province of South Africa. AIDS Patient Care \& STDs, 23, 357-364. http://dx.doi.org/10.1089/apc.2008.0201

[25] Fox, M.P. and Rosen, S. (2010) Patient Retention in Antiretroviral Therapy Programs up to Three Years on Treatment in Sub-Saharan Africa, 2007-2009: Systematic Review. Tropical Medicine and International Health, 15, 1-15. http://dx.doi.org/10.1111/j.1365-3156.2010.02508.x

[26] Greig, J., O’Brien, D.P., Ford, N., Spelman, T., Sabapathy, K. and Shanks, L. (2012) Similar Mortality and Reduced Loss to Follow-Up in Integrated Compared with Vertical Programs Providing Antiretroviral Treatment in Sub-Saharan Africa. JAIDS Journal of Acquired Immune Deficiency Syndromes, 59, 92-98. http://dx.doi.org/10.1097/QAI.0b013e31824206c7

[27] Lamb, M.R., El-Sadr, W.M., Geng, E. and Nash, D. (2012) Association of Adherence Support and Outreach Services with Total Attrition, Loss to Follow-Up, and Death among ART Patients in Sub-Saharan Africa. PLoS ONE, 7, Article ID: 38443. http://dx.doi.org/10.1371/journal.pone.0038443

[28] Dearholt, S.L. and Dang, D. (2012) Johns Hopkins Nursing Evidence-Based Practice: Models and Guidelines. 2nd Edition, Sigma Theta Tau International, Indianapolis, IN.

[29] Laforest, R. and Orsini, M. (2005) Evidence-Based Engagement in the Voluntary Sector: Lessons from Canada. Social Policy \& Administration, 39, 481-497. http://dx.doi.org/10.1111/j.1467-9515.2005.00451.x

[30] Shdaimah, C. and Stahl, R. (2006) Reflections on Doing Phronetic Social Science: A Case Study. In: Schram, S.F. and 
Caterino, B., Eds., Making Political Science Matter: Debating Knowledge, Research, and Method, NYU Press, New York, 98-116.

[31] Babigumira, J.B., Sethi, A.J., Smyth, K.A. and Singer, M.E. (2009) Cost Effectiveness of Facility-Based Care, HomeBased Care and Mobile Clinics for Provision of Antiretroviral Therapy in Uganda. PharmacoEconomics, 27, 963-973. http://dx.doi.org/10.2165/11318230-000000000-00000

[32] Gruber, J. and Caffrey, M. (2005) HIV/AIDS and Community Conflict in Nigeria: Implications and Challenges. Social Science and Medicine, 60, 1209-1218. http://dx.doi.org/10.1016/j.socscimed.2004.06.053

[33] Mabude, Z.A., Beksinska, M.E., Ramkissoon, A., Wood, S. and Folsom, M. (2008) A National Survey of Home-Based Care Kits for Palliative HIV/AIDS Care in South Africa. AIDS Care, 20, 931-937. http://dx.doi.org/10.1080/09540120701768438

[34] Omaswa, F. (2006) Informal Health Workers-To Be Encouraged or Condemned? Bulletin of the World Health Organization, 84, 83. http://dx.doi.org/10.2471/BLT.05.027979

[35] Schneider, H. and Lehmann, U. (2010) Lay Health Workers and HIV Programmes: Implications for Health Systems. AIDS Care, 22, 60-67. http://dx.doi.org/10.1080/09540120903483042

[36] Adedimeji, A.A., Alawode, O.O. and Odutolu, O. (2010) Impact of Care and Social Support on Wellbeing among People Living with HIV/AIDS in Nigeria. Iranian Journal of Public Health, 39, 30-38.

[37] Ncama, B.P. (2007) Acceptance and Disclosure of HIV Status through an Integrated Community/Home-Based Care Program in South Africa. International Nursing Review, 54, 391-397. http://dx.doi.org/10.1111/j.1466-7657.2007.00560.x

[38] Sivaram, S., Zelaya, C., Srikrishnan, A.K., Latkin, C., Go, V.F., Solomon, S. and Celentano, D. (2009) Associations between Social Capital and HIV Stigma in Chennai, India: Considerations for Prevention Intervention Design. AIDS Education and Prevention, 21, 233-250. http://dx.doi.org/10.1521/aeap.2009.21.3.233

[39] Wouters, E., Meulemans, H. and van Rensburg, H.C. (2009) Slow to Share: Social Capital and Its Role in Public HIV Disclosure among Public Sector ART Patients in the Free State Province of South Africa. AIDS Care, 21, 411-421. http://dx.doi.org/10.1080/09540120802242077

[40] Ntseane, D., Nthomang, K., Segwabe, M., Jankey, O., Simbayi, L. and Strebel, A. (2010) Challenges Facing People Living with HIV and AIDS (PLWHA) in Botswana: Implications for Behavioural Risk Reduction Intervention. Journal of Social Development in Africa, 25, 71-96.

[41] Chang, L.W., Alamo, S., Guma, S., Christopher, J., Suntoke, T., Omasete, R., Montis, J.P., Quinn, T.C., Juncker, M. and Reynolds, S.J. (2009) Two-Year Virologic Outcomes of an Alternative AIDS Care Model: Evaluation of a Peer Health Worker and Nurse-Staffed Community-Based Program in Uganda. JAIDS Journal of Acquired Immune Deficiency Syndromes, 50, 276-282. http://dx.doi.org/10.1097/QAI.0b013e3181988375

[42] Bedelu, M., Ford, N., Hilderbrand, K. and Reuter, H. (2007) Implementing Antiretroviral Therapy in Rural Communities: The Lusikisiki Model of Decentralized HIV/AIDS Care. Journal of Infectious Diseases, 196, S464-S468. http://dx.doi.org/10.1086/521114

[43] Boulle, A., Van Cutsem, G., Hilderbrand, K., Cragg, C., Abrahams, M., Mathee, S., Ford, N., Knight, L., Osler, M., Myers, J., Goemaere, E., Coetzee, D. and Maartens, G. (2010) Seven-Year Experience of a Primary Care Antiretroviral Treatment Programme in Khaylitsha, South Africa. AIDS, 24, 563-572. http://dx.doi.org/10.1097/QAD.0b013e328333bfb7

[44] Helleringer, S., Kohler, H.P., Frimpong, J.A. and Mkandawire, J. (2009) Increasing Uptake of HIV Testing and Counseling among the Poorest in Sub-Saharan Countries through Home-Based Service Provision. JAIDS Journal of Acquired Immune Deficiency Syndromes, 51, 185-193. http://dx.doi.org/10.1097/QAI.0b013e31819c1726

[45] Jaffar, S., Amuron, B., Foster, S., Birungi, J., Levin, J., Namara, G., Nabiryo, C., Ndembi, N., Kyomuhangi, R., Opio, A., Bunnell, R., Tappero, J.W., Mermin, J., Coutinho, A., Grosskurth, H. and Jinja Trial Team (2009) Rates of Virological Failure in Patients Treated in a Home-Based versus a Facility-Based HIV-Care Model in Jinja, Southeast Uganda: A Cluster-Randomised Equivalence Trial. Lancet, 374, 2080-2089. http://dx.doi.org/10.1016/S0140-6736(09)61674-3

[46] Selke, H.M., Kimaiyo, S., Sidle, J.E., Vedanthan, R., Tierney, W.M., Shen, C., Denski, C.D., Katschke, A.R. and Wools-Kaloustian, K. (2010) Task-Shifting of Antiretroviral Delivery from Health Care Workers to Persons Living with HIV/AIDS: Clinical Outcomes of a Community-Based Program in Kenya. JAIDS Journal of Acquired Immune Deficiency Syndromes, 55, 483-490. http://dx.doi.org/10.1097/QAI.0b013e3181eb5edb

[47] Defilippi, K. and Cameron, S. (2010) Expanding the Reach of Palliative Care to Community-Based Home Care Programs. Journal of Pain and Symptom Management, 40, 3-5. http://dx.doi.org/10.1016/j.jpainsymman.2010.04.004

[48] Pearson, C.R., Micek, M.A., Simoni, J.M., Hoff, P.D., Matediana, E., Martin, D.P. and Gloyd, S.S. (2007) Randomized Control Trial of Peer-Delivered, Modified Directly Observed Therapy for HAART in Mozambique. JAIDS Journal of 
Acquired Immune Deficiency Syndromes, 46, 238-244. http://dx.doi.org/10.1097/QAI.0b013e318153f7ba

[49] Wouters, E., van Damme, W., van Rensburg, D., Masquiller, C. and Meuleman, H. (2012) Impact of CommunityBased Support Services on Antiretroviral Treatment Programme Delivery and Outcomes in Resource-Limited Countries: A Synthetic Review. BMC Health Services Research, 12, 194-211.

http://dx.doi.org/10.1186/1472-6963-12-194 
Scientific Research Publishing (SCIRP) is one of the largest Open Access journal publishers. It is currently publishing more than 200 open access, online, peer-reviewed journals covering a wide range of academic disciplines. SCIRP serves the worldwide academic communities and contributes to the progress and application of science with its publication.

Other selected journals from SCIRP are listed as below. Submit your manuscript to us via either submit@scirp.org or Online Submission Portal.
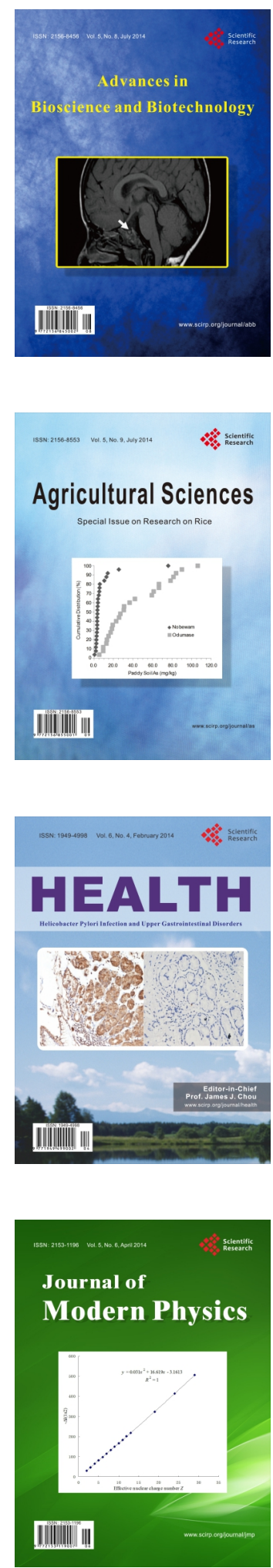
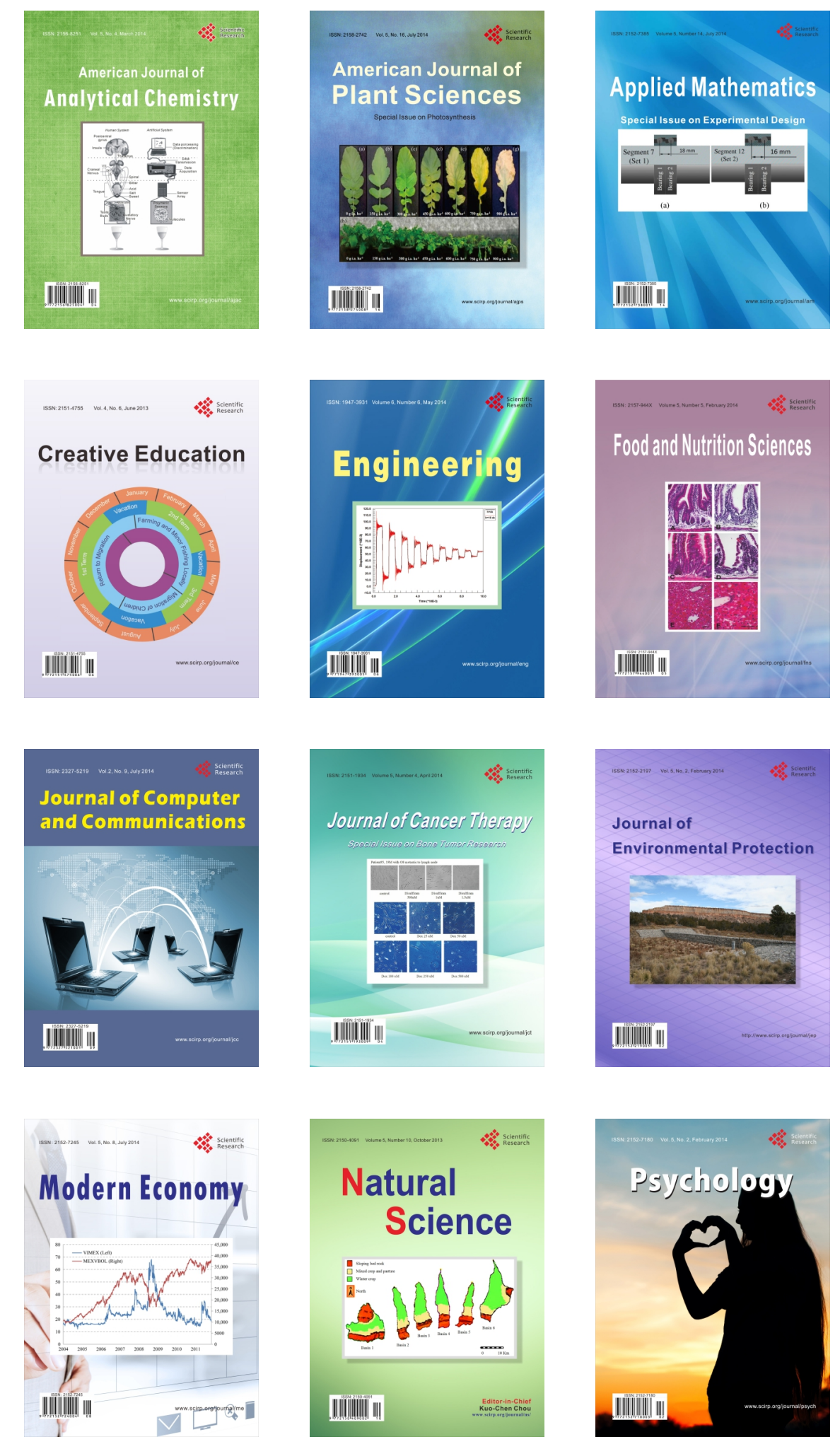